This is an Accepted Manuscript of an article published by Wiley in Economic Geography on 2020-02-20, available online: https://www.tandfonline.com/doi/ full/10.1080/00130095.2020.1715793

\title{
Exploring the causes and consequences of regional income inequality in Canada
}

\author{
Yannick Marchand \\ Department of Geography, McGill University \\ Jean Dubé \\ École supérieure d’aménagement du territoire et de développement régional, \\ Université Laval \\ Sébastien Breau* \\ Department of Geography, McGill University \\ and \\ Donald J. Savoie Institute, Université de Moncton \\ *Corresponding author (sebastien.breau@mcgill.ca)
}

Working Paper, Donald J. Savoie Institute

2 November 2019

\begin{abstract}
The recent surge in populist movements sweeping many countries has brought into focus the issue of regional inequality. In this paper, we develop a panel dataset for Canada that includes information on 284 regions observed at 5-year intervals (from 1981 to 2011) and estimate a series of spatial econometric models to study the causes and consequences of regional inequality. Our results draw attention to the fact that the rise in inequality at the national-level has been accompanied by greater cross-regional inequality. Differences in the level of economic development, precariousness of labour market conditions, socio-economic factors are among the key drivers of these regional patterns of inequality. We also find that the industrial mix of a region plays an important role in shaping its distribution of income: regions with high concentrations of manufacturing activities typically have lower levels of inequality whereas regions with high concentrations of tertiary services, arts and entertainment as well as knowledge intensive business services tend to have higher levels of inequality. In terms of the consequences of inequality, the growth/equity trade-off across Canadian regions varies significantly over the short- vs. medium-term horizons. In the short-run, our results suggest that inequality is positively related to regional economic growth. This response changes as we move to a medium-term horizon which suggests that as inequality persists over longer periods of time it has a negative and significant impact on regional growth trajectories. Panel vector autoregressive models are also used to further explore the direction of causality of the growthinequality relationship.
\end{abstract}

Keywords: regional inequality; Canada; causes; consequences. 


\section{Exploring the causes and consequences of regional income inequality in Canada}

\section{Introduction}

The issue of regional inequality appears to be gaining traction again. Indeed, while global inequality has been falling over the last few decades (Bourguignon 2012; Milanovic 2016;

Alvaredo et al. 2018), inequality within most of the world's leading economies has been on the rise. The era of convergence which characterized much of the mid- to late- $20^{\text {th }}$ century, where poorer regions within countries grew faster and caught up to richer ones, has given way to what has variously been dubbed the "great divergence" (Moretti 2012) or "great inversion" (Storper 2018). A new, more unequal and polarized geography of prosperity and opportunity has become the defining feature of the first two decades of the $21^{\text {st }}$ century.

This rise in within-country inequality has also been accompanied by a rise in regional resentment and much greater polarization of political attitudes and voting behavior (Spicer 2018). The Brexit vote in June of 2016 in which the UK electorate voted to leave the EU, the election of President Trump in November of that same year or the continued growing support for the Front National in France are well known examples of this (Essletzbichler et al. 2018; Gordon 2018; Lee et al. 2018). In each case, the populist surge has played an important role in shaping the outcome and shared a common regional narrative: voters in declining or lagging regions increasingly feel left-behind by the forces of globalization, rapid technological change and immigration. This new regional narrative reflects a growing "geography of discontent" (Los et al. 2017; Dijkstra et al. 2019) or the "revenge of places that don't matter" (Rodriguez-Pose 2018). Even The Economist (2016) has chimed in arguing that the growing problem of inter- 
regional inequality - and the lack of solutions to it offered by orthodox economic approaches should no longer be ignored.

While the winds of populism have yet to blow as strongly in Canada (Polese 2017), concerns are growing over the problem of regional inequality and its potential to ignite a much larger populist groundswell (Graves and Valpy 2018, 2019). Already, we have seen significant shifts in the provincial political landscape where highly charged populist rhetoric is central to the discourse of newly elected premiers in Ontario (Doug Ford in 2018), Québec (François Legault in 2018) and Alberta (Jason Kenney in 2019). Focusing on the case of Ontario, Taylor (2018) argues that the province's increasing political polarization is being driven by increasing inequality and the growing gulf dividing economically dynamic vs. stagnant regions. He also argues that such fault lines and widening territorial inequalities writ large will likely lead to more instability and political conflict across the country. Savoie (2019) goes even further arguing that the failure of national institutions to define and accommodate differences in regional circumstances poses one of the greatest threats to representative democracy in the country.

In light of these concerns, this paper seeks to contribute to our understanding of regional inequality in Canada by pursuing three main objectives. The first is to present an up-todate portrait of the regional dimensions of inequality across the country over the long-term (from 1981 to 2011). After identifying, describing and mapping changes to regional patterns of inequality, our second objective is to explain the drivers of these changes by estimating a series of spatial panel data models. In particular, we are interested in determining what set of forces, whether in terms of changes to the demographic profile, labour market conditions, institutional 
aspects and industrial composition of regions, played an important role in shaping the evolution of regional trajectories of inequality in the country. Answers to these questions will in turn lead us to the third objective of the paper which is to examine how inequality may affect the growth of regions. Here, we also use a panel vector autoregressive approach to shed light on the causal linkages of the inequality-growth relationship.

We begin in the following section by summarizing the literature on inequality from a Canadian perspective, paying particular attention to the regional dimensions of the problem. In section 3, we discuss some of the key methodological elements of the paper before presenting preliminary evidence of regional patterns of inequality in section 4 and outlining (in section 5) the modeling strategy adopted to study the causes and consequences of regional variations in inequality. The results of these models are presented and discussed in section 6 . Section 7 presents an exploratory analysis of the causal linkages between inequality and growth. A brief set of conclusions is offered in section 8 .

\section{An overview of the problem}

\subsection{Context: Income inequality in Canada}

Income inequality has increased considerably in Canada over the last 35 years. Looking at the Gini coefficient suggests that levels of inequality in the country are $15 \%$ higher today than in 1981, with much of this growth taking place from the early-1990s to the mid-2000s, driven by the rise in incomes at the top of the distribution. As Lemieux and Riddell (2016) show, virtually all (75\%) of the income gains in Canada over this period of time have gone to the top $10 \%$ of 
earners while by itself, the top $1 \%$ of earners have captured $37 \%$ of total income growth in Canada (see also Fortin et al. 2012; Veall 2012; OECD 2014a; Osberg 2018).

Canada is not the only country to have experienced such an increase in inequality. Figure 1 shows broad trends in inequality across 19 OECD countries for which comparable statistics are available from the early-1990s to the late-2000s. Here, the columns indicate the percentage point change in the Gini coefficient and the share of top $1 \%$ incomes over time, ranked in order of the latter (using the left-side primary axis). While the overall level of inequality in Canada is just above the OECD-19 average (Gini coefficients for the late-2000s are shown as a black diamond using the right-side secondary axis), what is more remarkable is the speed of change in inequality. From 1990 to the late-2000s, Canada ranks second in terms of the percentage point change in Gini coefficient (following Sweden) and third in terms of the top $1 \%$ income shares (after the US and UK).

[Figure 1]

\subsection{On the causes and consequences of inequality}

Given such patterns of rising inequality, a large body of work has emerged dedicated to investigating its (i) causes and (ii) consequences. This work spans across a wide array of disciplines and while disagreement remains as to the relative importance of possible contributing factors, there is growing consensus around the view that no single factor can account for the underlying shifts in income inequality. 
Figure 2 provides a conceptual framework summarizing, from a regional perspective (more on this in the following sub-section), what are the most commonly identified underlying causes of inequality (see left-hand side of figure). These can be classified as global or macrolevel forces and more local factors. Technological change is considered one of the leading causes of rising inequality. The basic idea here is that there has been a broad shift in labour demand favoring those highly-skilled workers who perform cognitive non-routine tasks as opposed to those involved in more routine tasks that computers can do easily such as manual, clerical and assembly-line type jobs (Autor et al. 2003; Brynjolfson and McAfee 2014). Increased international trade and offshoring are related driving forces. Just like computers, tasks that can be carried out by workers in countries with lower-wages can lead to greater downward pressures on the domestic demand of manufactured goods. These are industries which in the past typically provided well-paid, stable, full-time, unionized blue-collar type jobs to workers in the middle and lower parts of the income distribution (Kemeny and Rigby 2012; Rodriguez-Pose 2012; Ezcurra and Rodriguez-Pose 2013). Changes in institutional factors, government tax and transfer systems, and regulatory environments more broadly are also central determinants explaining recent patterns of inequality (Hacker and Peirson 2010; Banting and Myles 2013).

[Figure 2]

While the abovementioned factors tend to be treated as global or macro-level forces, the degree to which they affect sub-national patterns of inequality also varies across regions within countries. That said, at the more local level, we can also identify three sets of related 
determinants. In terms of local economic and labour market conditions, there is a long-standing literature linking a region's level of development to income inequality (Kuznets 1955; Williamson 1965). Changes in a region's industrial composition and diversification are also linked to potential differences in the trajectories of inequality (Bartik 1996; Levernier et al. 1998; Boschma 2017). This is especially true for places where deindustrialization (i.e., with employment in manufacturing sectors in decline while service based sectors expand) is occurring at a rapid rate. Differences in the unemployment rate and employment precarity more broadly are other common underlying causes of regional inequality. A second set of driving forces involves supply-side factors such as regional age structures and the impact of population aging (Saillant 2016), the role women's increased labour force participation (McCall and Percheski 2010), shifts in the educational composition of the labour force (Boudarbat et al. 2006; Rodriguez-Pose and Tselios 2009) and disparities in earnings for immigrants and visible minority populations (Pendakur and Pendakur 2007). Finally, patterns of regional inequality are also going to be shaped by policies that reflect the local institutional context, either in terms of minimum wage legislation, the regulatory environment for labour union activities and tax and transfer systems. In this paper, our focus will be on determining which local factors (all highlighted in black in Figure 2) are key in explaining regional patterns of inequality in Canada.

The right hand side of Figure 2 summarizes the arguments as to why inequality matters in terms of potential outcomes. The literature has expanded rapidly in this area of research over the last two decades, especially in the health geography and epidemiology fields (Cavanaugh and Breau 2018). In our case, we are particularly interested in the relationship linking income inequality to regional growth patterns. As was argued earlier, growing regional 
inequalities are increasingly seen as an important source of instability and populist resentment. Yet while many regional scholars have looked at the underlying causes of rising inter-regional inequality, much less attention has been paid to its consequences on growth (Rodriguez-Pose 2018; Spicer 2018). Moreover, most of the literature that does exist tends to present mixed results based on correlations that suggest a one-way causal relationship between growth and inequality (e.g., Fallah and Partridge 2007; Forbes 2000; Panizza 2002; Partridge 1997, 2005; Rupasingha et al. 2002). This is a by-product of the regression approach typically followed by regional studies which borrow from cross-country growth models (Atems and Jones 2015). In this paper, we seek to investigate both (i) how economic development may affect regional patterns of inequality and (ii) how patterns of inequality may also affect regional growth trajectories.

\subsection{Scales of analysis: The missing regional dimension}

In the vast literature on inequality, if there is a tendency for economists to emphasize the national scale of analysis, the work of geographers, sociologists and planners has mainly privileged the urban scale (Lobao et al. 2008). Within the Canadian context, there is a wellestablished literature exploring patterns of inequality within metropolitan areas (e.g., Bourne 1993; MacLachlan and Sawada 1997; Myles et al. 2000). More recent work by Hulchanski (2007), Chen et al. (2012), Walks (2015) and Breau et al. (2018) points to the continued increase in socio-spatial inequality and polarization within cities. This in turn has led some to describe such trends as signaling a 'new urban crisis' as cities are fragmenting into a new kind of divided patchwork metropolis (Florida 2017; OECD 2018). 
But as the national and intra-metropolitan scales have both received considerable attention, there remains an important knowledge gap as to what is happening 'in-between', both in terms of understanding the causes and consequences of regional differences in inequality (Chokie and Partridge 2008; Lobao et al. 2008; Cavanaugh and Breau 2018). Seminal work by Ray and Brewis (1976) drew early attention to this problem and pointed to the need for more data on the regional structure of the Canadian space-economy. Since this initial call for action, only a small number of studies focusing on the causes of inequality at the provincial level have been realized. ${ }^{1}$ (e.g., Finnie 2001; Gray et al. 2004; Breau 2007; Murphy and Veall 2015; Fortin and Lemieux 2015). These studies find evidence of growing inter-provincial differences in the distribution of incomes which are in turn linked to a range of factors identified in Figure 2.

Below the provincial scale, the literature on the causes of inequality is even more sparse. MacPhail (2000) used the Survey of Work History and the Labour Market Activities Surveys to build a set of Gini coefficients and labour force characteristics for 64 'broad' regions across the country over the 1980 s period. Her results suggests that the main drivers of the rise in inequality across Canadian regions were higher unemployment rates and declining unionization rates. A few years later, Chokie and Partridge (2008) examined regional differences in low-income cut-off rates (LICOs) for some 2,400 communities (i.e., census-consolidated subdvisions). While LICOs are income thresholds used to produce a metric that resembles poverty rates (i.e., focusing on the dynamics of the lower tail of the income distribution and not

\footnotetext{
${ }^{1}$ It is important to note here that we are emphasizing studies on the distribution of incomes and not disparities in terms of means incomes or per capita GDP. Considerable attention has been given to the latter 'convergence' debate in Canada (e.g., Coulombe 1999; Breau and Saillant 2016) but that is not the centre of our attention here.
} 
the entire distribution such as Gini coefficients), their analysis provided one of the richest spatial tapestry's of the causes of differential community poverty rates in the country. Results showed that low-income rate differentials where affected mainly by local economic conditions in the short-term, with demographic factors becoming relatively more important over the longterm. Finally, in a pilot study using the $20 \%$ long-form sample of the Census, Breau (2015) examined the causes of regional variations in inequality across Census Divisions from 1996 to 2006 ( $n=287$ regions). He found that economic development, industry mix, unemployment, ethnic composition, the distribution of educational attainment and population density were all consistent predictors of inequality. With only a 10-year window of analysis, however, the time series dimension imposed limitations in terms of the modeling possibilities offered.

On the consequences side of the debate, much of the empirical literature in Canada has focused on studying the health or social impacts of inequality with, to the best of our knowledge, only one attempt to investigate the impacts of inequality on regional economic growth patterns in Canada. Using data covering the 1977 to 2006 period, Dahlby and Ferede (2013) apply a standard OLS growth regression modeling approach to examine the effects of inequality on GDP per capita across provinces. They find only weak evidence of a positive relationship between the initial level of inequality and subsequent provincial economic growth. The significance of this finding disappears when further controls are added to the model, a finding that is not unexpected given the small cross-sectional sample (with $n=10$ ) used for modeling purposes.

In this paper, we build on the aforementioned studies and extends the analysis in three main respects. First, the development of a geographically detailed regional dataset over a 
longer time-period allows for more robust spatial panel data modeling strategies to be applied and therefore reduces the potential for omitted variables bias. Second, this is the first time the analysis of regional inequality is carried out with a detailed set of industrial controls to study the effects of differences in wages across the industrial composition of regions. Third, it is also the first time the impacts of divergent patterns of inequality on regional economic growth are estimated in Canada.

\section{Data sources, regions and industry definitions}

\subsection{Data sources}

To develop a long-term perspective of the causes and consequences of regional inequality, our analysis relies on the 20 percent long-form sample of the Census of 1981, 1986, 1991, 1996, 2001 and 2006 as well as the 2011 National Household Survey. The benefits of working with the 20\% Census micro-data files have already been documented elsewhere (Frenette et al. 2009) ${ }^{2}$. From our point of view, in addition to containing a detailed breakdown of the income (which is not top-coded ${ }^{3}$ ) and socio-economic characteristics of a large number of respondents (between 5 to 6.7 million Canadians across the different census cycles), it provides information on their place of residence. This is particularly important for constructing a geographically consistent panel of inequality indicators at the regional-level.

\footnotetext{
${ }^{2}$ More details relating to the nature of the Census and NHS data are available in Appendix.

${ }^{3}$ Total income, which is the primary income concept used in this paper, refers to employment earnings (i.e., wages and salaries) and self-employment income received by individuals, as well as dividends and other investment incomes, retirement pensions and government transfer payments (e.g., Old Age Security, Canada and Quebec Pension Plans, Employment Insurance benefits, child benefits). Furthermore, income is measured on a pre-tax basis and for each census, it is reported for the calendar year prior to the census.
} 
Regions themselves are defined as Census divisions. Census divisions (CDs) represent groups of neighbouring municipalities (i.e., Census subdivisions) joined together for the purposes of regional planning and managing common services (Statistics Canada, 2017). CDs are administered under provincial jurisdiction and their boundaries are subject to change over time through annexation, partial annexation, dissolution or creation of CDs or smaller geographic units. In our case, the number of CDs in $1981(n=266)$ increased to 293 by 2011. Although mainly small geographic variations are found from one census year to another, comparisons over the broader 30-year horizon reveal much more variation in CD boundary changes: in all, $42 \%$ of CDs in Canada saw part of their boundaries redrawn over the 30 -year period of study.

To address these changes in CD boundaries and maintain longitudinal consistency over time, a GIS was used in conjunction with smaller Census subdivision units to reconstruct a consistent panel of regions. The 2011 CD master boundary file was used as our guide although a few CSD boundary changes that were not retraceable or incongruent from one census cycle to the next forced us to aggregate some units together. Ultimately, we end up with a time consistent panel of $n=284$ regions $^{4}$.

Like regions, we also need to address the challenge of changing industrial classifications over time. In Canada, census responses to industry of work information from 1981 to 2001

\footnotetext{
${ }^{4}$ Census Divisions (CDs) are akin to counties in the US and UK. They are aggregates of adjacent census subdivisions ( $n=5,253$ CSDs in 2011) which are in turn the spatial units used to define the boundaries of census metropolitan areas (CMAs) and census agglomerations (CAs) (i.e., the country's urban centres). While CDs are the preferred units of analysis for regional studies and regional policy development in Canada, they do not correspond perfectly with the definition of CMAs or CAs. For instance, Montreal as a CMA consists of 27 different CSDs (with a total population of roughly 3.9 million in 2011). These 27 CSDs are part of 11 different CDs (the core of which - roughly $60 \%$ of the population in 2011 - consists of the Montreal and Laval CDs).
} 
were coded using the Standard Industrial Classification (SIC-1980 with $n=286$ industries at the four digit level) before being replaced in 1997 by the North American Industry Classification System (NAICS with $n=324$ industrial sectors). To get around this change in classification and build a correspondence between industrial sectors, we aggregated the detailed industrial information from both the SIC and NAICS to 17 broad industry sectors that are consistent over time. Note that manufacturing activities were further sub-divided into five categories following the OECD's (1987) methodology of focusing on the primary factors that influence the competitiveness of each industry. These include resource-based activities that are characterized by the importance of access to natural resources (e.g., aluminium smelting), labour-intensive industries which depend heavily on labour costs (e.g., clothing, footwear), scale-intensive industries that are defined primarily by long production cycles (e.g., steel), differentiated goods industries which manufacture goods in response to varied demand characteristics (e.g., machine tools) and science-based industries where the application of scientific advances is central (e.g., pharmaceuticals). To the best of our knowledge, no other study in Canada has assessed the potential impact of industrial composition effects on regional inequality using such a detailed classification.

\section{Some preliminary evidence}

We begin the analysis by looking at a snapshot of broad patterns of regional inequality in Canada in 2011 (see Figure 3). Here, the Gini coefficient for each CD is shown, grouped by territories and provinces from the Pacific to the Atlantic coasts. Each regional Gini coefficient is also weighted by population size and is benchmarked against the value of the national Gini 
coefficient shown as the dashed horizontal line running through the graph. Two things stand out. First, the east-west divide originally documented by Breau (2015) persists through 2011 (more on this below). Census divisions east of the Ottawa River (which for most of its length defines the border between the provinces of Ontario and Quebec) typically have much lower levels of income inequality than do regions west of the river. Indeed, only six regions in eastern Canada have a Gini coefficient on par with or above the national average. In contrast, there is much more heterogeneity and spread in the values of inequality across regions in Ontario, the Prairies and British Columbia, with more than a dozen of these regions registering levels of inequality that are at least $10 \%$ higher than the national figure. The second observation to note is the apparent relationship between inequality and population size. Most large metropolitan CDs have levels of inequality that are higher than the national average whereas most regions registering lower levels of inequality are typically smaller and rural in nature. Bolton and Breau (2012) documented a similar inequality-population size relationship within the country's urban hierarchy, though the evidence presented here suggests that the gradient extends beyond to an urban-rural continuum ${ }^{5}$.

\section{[Figure 3]}

If Figure 3 presents a static snapshot of regional variations inequality, Figure 4 provides a more general picture of how inequality has evolved from 1981 to 2011 . Three indicators are presented (all based on total income measures). The top two lines, which are based on the left-

\footnotetext{
${ }^{5}$ Using a global dataset from the UN's World Urbanization Prospects, Castells-Quintana (2018) has recently found evidence of a U-shaped relationship where inequality, after first declining, tends to increase with average city size. Whether this relationship holds within the Canadian urban hierarchy is a question to be further investigated in a future paper.
} 
side axis, show the 5-year Census based Gini coefficient and the Gini coefficient from the Canadian Income Survey (Table 206-0033). While the latter offers more texture in terms of annual variations in inequality, its smaller sample size does not allow for detailed geographical breakdowns. For the purposes of this study, the point is that both measures essentially track the same broad pattern: inequality in Canada increased rapidly from the late 1980s thru the 1990s before peaking and stabilizing in the mid-2000s. The drop in inequality from 2006 to 2011 largely reflects the compression of wages following the 2008-09 Great Recession.

[Figure 4]

More interesting is the bottom dashed line that shows the coefficient of variation for regional measures of inequality (based on the right-side secondary axis). Here, we see clearly that the rise in the level of inequality at the national level has also been accompanied by greater cross-regional inequality. Regions are, in other words, increasingly on divergent paths in terms of their trajectories of inequality, with the range of regional inequality values widening over time. This trend, which started in the early 1990s, is a reversal of earlier forces of convergence which had been at work since the 1960s (Coulombe 1999; Breau and Saillant 2016) and provides further evidence of the 'great inversion' others have observed in the US and EU (lammarino et al. 2017; Storper 2018).

Another way of visualizing such disparities in regional trajectories of inequality is shown in Figure 5. This map presents a simple 5-pronged classification for all 284 CDs based on whether inequality increased (red), remained stable (hollow) or declined (blue) from 1981 to 2011. The darker shaded the area, the more pronounced the change in inequality. In terms of 
changes over time, we again find traces of an east-west divide as most CDs in Alberta and British Columbia experienced rapid growth in inequality compared to several regions in Quebec where inequality declined. Several other regions also standout: in Saskatchewan and Manitoba, there are a number of CDs that experienced a decline in inequality over the 30 -year period whereas inequality increased significantly in many regions of southern Ontario as well as Newfoundland. Likewise, the urban-rural divide is noticeable as large metropolitan areas mainly show up in dark red having experienced rapid increases in inequality (Toronto, Calgary, Montreal and Vancouver all rank within the top 10 regional increases in inequality).

The map also brings to light another issue that until now has remained unstated: the problem of spatial autocorrelation. In Figure 5, regions that experienced rapid increases (declines) in inequality tend to be located near other regions with similar increases (declines). To test this more formally, we calculated the Moran's / statistic using a Rook's first order spatial weights matrix which yielded a positive and significant value of $0.433^{6}$. Such spatial dependence among the values will be important to keep in mind for the models we estimate below.

[Figure 5]

\section{Model specifications}

\footnotetext{
${ }^{6}$ We also calculated the Moran's I independently for Gini coefficients in each census cycle and all values were positive and significant (ranging from 0.487 to 0.595 ). Similar results were also found for the Theil index.
} 
Given the panel structure of the dataset and the presence of spatial autocorrelation in the key variable of interest, two benchmark models are developed to investigate the causes and consequences of inequality at the regional-level in Canada. Based on the multi-dimensional conceptual framework presented in section 2, our point of departure to study the determinants (i.e., causes) of regional inequality is a fixed effects spatial error model. ${ }^{7}$ specified as:

$$
\begin{gathered}
G I N I_{i t}=\alpha+L M E_{i t} \beta+\operatorname{SOCDEM}_{i t} \delta+I N D_{i t} \eta+I N S T_{i t} \gamma+\mu_{i}+\pi_{t}+\phi_{i t}, \\
\text { where } \phi_{i t}=\lambda \sum_{j=1}^{N} W_{i j} \phi_{j t}+\varepsilon_{i t} .
\end{gathered}
$$

Here, $i$ is an index representing Census Divisions (i.e., the cross-section of regions, with $N=284$ ) and $t$ is an index of the temporal dimension (i.e., 5-year census cycles, with $T=7$ ). The dependent variable is the measure of inequality (i.e., the Gini coefficient) for each $C D$. On the right-hand side of the equation, we include four sets of independent variables. We examine the impact of factors tied to changes in regional labor market and economic (LME) conditions by including variables on the median wages (as a proxy for a region's level of economic development), median wages squared, the unemployment rate, the percentage of part-time and self-employed workers (see Table 1 for more details). SOCDEM is a vector of controls for socio-demographic variables such as the female participation rate, the percentage of visible minorities, the education ratio (i.e., this is a proxy for educational inequality defined as the ratio of individuals with less than a high school degree or equivalent plus those with a bachelor's

\footnotetext{
${ }^{7}$ Both fixed effects spatial lag and spatial error models were initially estimated and a robust Lagrange Multiplier test was applied to determine which type of spatial interaction effects should be accounted for (the diagnostic favouring the FE SEM modeling approach). Hausman's specification test also revealed that a FE approach was favorable (see Anselin et al. 2008; Elhorst 2009).
} 
degree or higher to the remaining population) less than a high school degree and the percentage of population with a bachelor's degree or more, the percentage of population aged $<15$ years (young) and > 64 years (senior). Different industry (IND) variables (as defined above) are included in the model to see if variations in inequality are also linked to differences in regional industrial composition. Finally, institutional (INST) controls for minimum wages, unionization rates and per capita transfers to persons are used as provincial contextual variables in the model. The term $\mu_{i}$ represents region-specific fixed effects, $\pi_{t}$ are time fixed effects (i.e., decade dummies) and $\varphi_{\text {it }}$ reflects the spatially autocorrelated error term with $\lambda$ as the spatial autocorrelation coefficient. $W_{i j}$ represents an element of the spatial weights matrix W which is defined using a Rook's $1^{\text {st }}$ order contiguity criterion (that is, $W_{i j}=1$ when $i$ and $j$ are neighbors, and $W_{i j}=0$ when they are not).

\section{[Table 1]}

Turning our attention to the consequences of inequality on regional economic growth, the second spatial panel model we estimate is specified as:

$$
\begin{gathered}
\Delta G R O W T H_{i t}=\alpha+\rho \sum_{j=1}^{N} W_{i j} \Delta G R O W T H_{i t}+\operatorname{GINI}_{i t-1} \psi+\operatorname{ECON}_{i t-1} \theta+\operatorname{LME}_{i t-1} \beta+ \\
\operatorname{SOCDEM}_{i t-1} \delta+I N D_{i t-1} \eta+I N S T_{i t-1} \gamma+\mu_{i}+\pi_{t}+\varepsilon_{i t}
\end{gathered}
$$

where $\triangle G R O W T H_{i t}$ represents the annual average growth rate of median total income for region $i$ over the period $t-1$ to $t$. One of the key findings to emerge from the empirical literature on the relationship between inequality and growth is that the effects of inequality will vary 
depending on the time period under consideration (Forbes 2000; Panizza 2002; Partridge 2005).

To distinguish between the effects of inequality on short- and medium-term regional growth trajectories, growth cycles are defined over two different periods: 5-year and 10-year periods, respectively. The model defined in Eq. (2) is a fixed effects spatial lag model. ${ }^{8}$ such that the first independent variable on the right hand side of the equation represents the spatial lag of the dependent variable with $\rho$ as the spatial autoregressive parameter associated with the $W_{i j}$ spatial weights matrix (as defined above). All independent variables included in this model are measured during period $t-1$. The Gini coefficient is our main variable of interest here and $\psi$ is interpreted as a measure of the correlation between changes in inequality over time and changes in growth within a given region (Forbes 2000; Panizza 2002). ECON it-1 $_{1}$ is a proxy for a region's level of economic development (i.e., the natural log of median income) and $L M E_{i t-1}$, SOCDEM $M_{i-1}, I N D_{i t-1}$ and INST $T_{i t-1}$ are matrices of additional controls defined as before. $\mu_{i}$ is the region fixed effect, $\pi_{t}$ are decade dummies and $\varepsilon_{i t}$ is the usual error term.

\section{Results}

\subsection{Drivers of regional inequality}

Table 2 presents the results for the fixed effects spatial error model, from the more parsimonious model estimates of Eq. (1) to the full specification with detailed industrial mix shares. Across all three models, estimates for the labour market, economic and sociodemographic variables are as expected. Although the effect is modest, regions with higher

\footnotetext{
${ }^{8}$ We again followed the usual practice of beginning by estimating both a spatial lag and spatial error model before applying the Lagrange multiplier tests to discriminate between the two forms of spatial autocorrelation (Anselin and Florax 1995). In this case, the spatial lag approach is preferred to the spatial error models.
} 
levels of economic development (as proxied by median wages) tend to have higher levels of inequality. This is not unexpected given our discussion of Figure 3 where CDs with the highest levels of inequality include most of the larger and high wage metropolitan areas in the country. The positive and significant coefficient on the squared value of median wages for the fully specified model is interesting as it suggests that, in contrast to Kuznets' famous inverted Ucurve, inequality can continue to increase even at advanced stages of economic development. This echoes the notion that patterns of inequality may instead follow a horizontal S-shaped trajectory (Piketty 2014) or what Milanovic (2016) has called 'Kuznets waves' of alternating cycles of decreasing and increasing inequality. Not surprisingly, we also find evidence that more precarious labour market conditions (i.e., higher unemployment and part-time rates) are associated with higher levels of regional inequality.

[Table 2]

In terms of the socio-demographic drivers of regional inequality, our results point to a positive association between female participation rates and inequality. Such a finding is unexpected but may point to the fact that there are important regional differences when women enter the labour market in terms of their skill sets and part- vs. full-time status, or the continued existence of significant wage gaps across certain occupations that may be more pronounced in certain regions than others (Moyser 2017). In-line with earlier findings by Breau (2015), regions with higher shares of visible minorities also have higher levels of inequality. Evidence presented in Picot et al. (2008) shows that the relative poverty rates of recent immigrants (compared to Canadian-born) were actually higher in the 2000s than in the 1990s. 
Likewise, Pendakur and Pendakur (2011) find that Aboriginal people continue to face significant wage gaps in comparison to Canadian-born majority groups of workers. The polarization of educational attainment within regions is another cause of rising inequality, as are differences in their demographic composition (i.e., age structures).

For the most part, the institutional variables have the expected signs. Regions with higher minimum wages and unionization rates typically have lower levels of inequality. While per capita income transfers to persons have a dampening effect on inequality in the second model (as expected), this result no longer holds when we move to more detailed industrial controls.

As argued earlier, one of the novelties of this study is to present a set of estimates on the impact of differences in industrial composition on regional inequality (see columns two and three). It is important to note that we leave out the share of workers employed in primary sector activities as our industrial benchmark for the models estimated. Similar to the findings of MacPhail (2000) and Breau (2015), the coefficient estimate for secondary sector activities is negative and significant (column 2). It thus appears as though the deindustrialization of regions continues to be one of the main drivers of increasing inequality. More specifically, glancing at the estimates of the OECD based sub-categories of manufacturing (column 3 ), we see that both resource- and scale-intensive industries are important sectors of activities which allow for a more equal distribution of wages. The same is true of labour-intensive industries, which taken together reflect traditional sectors of employment for middle-class workers. In contrast, regions with larger shares of tertiary sector employment as a whole tend to be associated with higher levels of inequality. 
Finally, while our aggregate estimate for quaternary sector activities is not significant (see column 2), the industrial breakdown in column 3 again offers interesting insights. In-line with the literature on the top $1 \%$ and the importance of the finance and insurance industries within this constituency (see Fortin et al. 2012; Tridico 2018), we find a significant influence exerted by this sector on regional differences in inequality. Recall that the FIRE variable reflects the increased prominence of the financial sector across Canadian regions, a small number of which have particularly high concentrations of FIRE activities (case in point, five of the top ten census divisions with the highest shares of workers in FIRE industries are in the Greater Toronto Area: Toronto, York/Richmond Hill, Halton/Oakville, Durham and Peel/Mississauga). As compensation in this sector continues to soar, beyond what is expected in terms of labour productivity, the shift towards financialization is one of the key drivers behind regional variations in income inequality. In contrast, regions with higher shares of public administration employment have lower levels of inequality. Such a finding gives credence to well known arguments that the decentralization of government jobs can serve as an instrument in the fight against regional inequality (see Savoie 2017). The coefficient estimate for our arts and entertainment variable is positive and significant. This is an interesting finding which harks back to Rosen's (1981) theory of 'superstars' wherein the distribution of income in certain kinds of economic activities is highly concentrated among a few individuals. A similar outcome is also found for regions with higher concentrations of knowledge intensive business services (KIBS). Although there are few studies directly examining the link between innovation and inequality, this finding supports evidence from Lee $(2011 ; 2016)$ that regions in Europe with higher concentrations of employment in KIBS tend to have more unequal distributions of wages. 


\subsection{Consequences of regional inequality}

Now that we have a better idea of what the main determinants of regional inequality are in the Canadian context, our focus turns to examining the impacts of increasing inequality. Table 3 presents the findings for our second model (Eq. 2) with the first two columns reporting estimates for the short-term effects using a 5-year growth cycle for the average annual compound growth rate. Both in the case of the parsimonious and full model specifications, the coefficient on the Gini coefficient is positive and significant. Over the short-term, the implication is that regions with higher levels of inequality are experiencing higher rates of economic growth. The negative and significant coefficient on the level of income in the preceding period is an indication that there is some conditional convergence among the regions over the short-term. The socio-demographic variables included in column 2 further suggest that regions with higher female participation rates and younger age structures tend to experience stronger growth. In contrast, regions where differences in educational attainment are more pronounced see slower growth rates.

[Table 3]

Moving to the medium-term effects (see columns 3 and 4), the results are quite different. Here, the coefficient estimates for the Gini are both negative and significant. This suggests that over the longer-term, structurally embedded inequality (i.e., which persists over time) can be detrimental to the economic growth of regions. Such a finding is consistent with 
the evidence brought forth by Panizza (2002) and Partridge (2005) for US states. It is also interesting to note that over the longer-term there is some evidence of a negative (though only weakly significant) relationship between the percentage of seniors and regional growth. Such a finding does not bode well for the economic future of many Canadian regions, especially in the eastern parts of the country where the population is set to age at a much faster rate than elsewhere (Saillant 2016).

The above estimates provide a first glimpse into the relationship between growth and inequality in Canada. One of the consensuses to emerge from the broader empirical literature on the growth/equity trade-off is that modeling results tend to be sensitive to small changes in specifications (see, in particular, Panizza 2002 and Partridge 2005). To address some of these concerns, Table 4 provides a summary of sensitivity tests conducted on the parsimonious version of Eq. (2) which is re-estimated with various modifications to the original specification (though note that all models are re-estimated using a fixed effects spatial lag). In general, the results for the 5- and 10-year growth cycles are robust to changes in variables and support the findings reported in Table 3. Across both the short- and medium-term, re-estimating the models using different spatial weights matrices did not have an impact on the sign or significance of our measure of inequality. It is interesting to note, however, that the mediumterm model results are more sensitive to the choice of inequality indicator and income concept used for the growth variable and Gini coefficients. Indeed, the statistical significance of our coefficient estimate for the impact of inequality over the 10-year growth cycle drops considerably when using the Theil index and is not significant with the GE(2) measure. The coefficient estimate for the Gini coefficient based on wages (instead of total income) is also 
only significant at the .10 level. While such results may seem trivial at first, they do serve to remind us that minor changes to the econometric specification used can have important impacts on the estimates of the growth-inequality relationship.

[Table 4]

\section{Further examination of the causal linkages between inequality and growth}

It is also important to remember that in the previous sections, the relationship between inequality and growth is examined using two different model specifications. In Eq. (1), the level of inequality for a region is regressed against its level of economic development (proxied by median incomes) and the square of median incomes at the initial time period. These variables are included to reflect the curvilinear relationship between income inequality and economic development as theorized by Kuznets' well-known inverted-U curve (Kuznets 1955; Moller et al. 2009). Eq. (2), on the other hand, follows the traditional growth-efficiency literature and specifies a region's growth over time as a function of previous $(t-1)$ levels of inequality.

To further explore the causal linkages between inequality and growth, we follow Atems and Jones (2015) and estimate a set of panel vector autoregressive (PVAR) models. Given that PVAR models describe the joint generation process of the dependent variables over time, they are often used in econometric analyses to shed light on underlying Granger causality (Granger and Newbold, 1986; Lütkepohl 1993; Hamilton 1994). The structure of the PVAR models we estimate here is specified as:

$$
\text { GINI }_{i t}=\alpha_{1}+\beta_{11} \text { GINI }_{i t-1}+\beta_{12} \text { GROWTH }_{i t-1}+\varepsilon_{1 t} \text {, }
$$




$$
\text { GROWTH }_{i t}=\alpha_{2}+\beta_{21} \text { GROWTH } H_{i t-1}+\beta_{22} \text { GINI }_{i t-1}+\varepsilon_{2 t}, \quad \text { Eq.(4) }
$$

where each variable is defined as before. We also estimate a slightly augmented version of the model whereby the lag of median total income is added on the right-hand side as a further control in both equations (this is standard practice for growth models). Ideally, we would be able to add more control variables to the models but given our limited number of time series observations (especially when looking at regional growth rates defined over 10 years) we are constrained to estimating simple PVAR structures.

Table 5 shows the estimation results for both sets of models. If we begin by looking at the short-term (5-year) periods (see panel A), none of our PVAR estimates are significant for the parsimonious model. That said, moving to the augmented model, the evidence suggest that inequality Granger causes growth while growth does not appear to Granger cause inequality. In the case of the medium-term (10-year) periods (see panel B), the causal structure is different and appears to be bidirectional. For both the parsimonious and augmented models, the results suggest (i) a positive and significant association between the lag of growth and inequality and (ii) a negative and significant association between the lag of inequality and regional growth. The flip on the sign for our estimate of the lag of inequality from the short- to the medium-term growth models echoes our findings presented in the previous section.

[Table 5] 
In closing, we wish to emphasize that the results presented here are meant to be exploratory of the inequality-growth causal linkages. As with any assessment of Granger causality, lead-lag relationships will depend on the set of variables included in the VAR models as well as the length of the lags themselves (Lütkepohl 1993; Eichler 2013). Again, we are constrained by the fact that the Census data is collected for 5 -year intervals which means that our longitudinal dimension (over the 1981 to 2011 period) is limited for such structural analysis. While our results are useful as a first approximation of how past values of inequality and growth can be helpful in 'predicting' future values of inequality and growth, a more robust analysis would require either annual data or a longer time series of census cycles (neither of which are possible at the present time).

\section{Conclusion}

Widening income inequality is of growing concern in Canada. Since the mid-1990s alone, inequality at the national level has increased by $11 \%$, which is more than five times higher than the OECD average country increase of $2 \%$ (OECD 2014b). Within this broad increase, we have also seen that there is growing concern about the rise of regional inequalities across the country though most of the literature so far has focused on documenting growing disparities between provinces in terms of differences in per capita gross domestic product.

In contrast, this paper set out to investigate differences in the distribution of income using a finer geographical scale of analysis. To do so, a panel of consistently defined regions was developed using Census and NHS micro-datafiles for the period 1981 to 2011 . Three key sets of findings were derived from the analysis of this panel. 
First, in describing the spatial patterns of the distribution of income across Canada, it is clear that the regional trajectories of inequality are increasingly diverging as the range of regional Gini coefficient values is widening over time. We find evidence supporting Breau's (2015) claim of an east-west divide, where regions in Alberta and British Columbia experienced more rapid increases in inequality compared to regions east of the Ottawa River. Likewise, an urban-rural divide is also evident, as inequality in large metropolitan areas have seen their levels of inequality rise more rapidly than smaller and predominantly rural areas.

Second, we turned our attention to examining the various factors that give rise to such observed differences in patterns of regional inequality. This was done with the help of a spatial panel modeling approach that allowed us to exploit the richness of both the cross-sectional and longitudinal variation of our regional observations. Among the key variables identified as driving differences in the distribution of income are a region's level of economic development, the precariousness of its labour market and socio-demographic factors such as differences in female participation rates, visible minorities, education and age profiles. We also find important differences in terms of how the industrial composition of regions affects levels of inequality. Regions with high concentrations of secondary sector activities typically have lower levels of inequality whereas regions with high concentrations of tertiary and quaternary sector activities, in particular finance, insurance and real estate, arts and entertainment and knowledge intensive business services tend to have more unequal income distributions. These are the first set of results to explicitly link shifts in industrial activities to regional patterns of inequality in Canada. 
Third, what does the observed rise in inequality mean for the future economic growth of regions? We provide a first attempt at answering this question by distinguishing between the potential short- and medium-term effects of inequality on regional growth. Our findings suggest that over the short-run inequality appears to be positively related to regional growth. This result changes, however, over the medium-term as the inequality response becomes negative. In other words, persistently high levels of inequality over time appear to have a negative impact on regional growth trajectories. Moreover, our findings suggest that the effect of spatial dependence in these growth trajectories is quite strong. How inequality affects growth in one region has important repercussions in shaping the inequality-growth relationship in neighbouring regions. Again, while we caution that these findings are preliminary and that much more detailed analysis of the growth/equity trade-off link across Canadian regions is required in the future, modeling efforts to do so should at the very least control for spatial autocorrelation.

In the end, the results presented in this paper highlight the fact that the regional question should not be ignored in policy debates about the future well-being of Canadians. Since the 1990s, economic and social policies across the country have been developed on the premise of spatially-blind frameworks that are focused on achieving greater efficiency rather than equity. We echo Bradford (2011) and lammarino et al. (2017) in arguing that place needs to be brought back in in order to tackle the problem of increasing regional inequality. The institutional variables in our models showed they can play an important role in dampening inequalities. Both federal and provincial levels of government should therefore revisit their 
policy toolboxes to consider alternative approaches that pursue efficiency and equity goals at the same time. 


\section{Bibliography}

Alvaredo F, Chancel L, Piketty T, Saez E, Zucman G (2018) The World Inequality Report 2018.

Anselin L, Florax R. (1995) Small sample properties of tests for spatial dependence in regression models: Some further results. In: Anselin L, Florax R (eds) New directions in spatial econometrics. Springer, Berlin.

Anselin L, Le Gallo J, Jayet H (2008) Spatial panel econometrics. In: Matyas L, Sevestre P (eds) The econometrics of panel data - Fundamentals and recent developments in theory and practice. Springer, Berlin.

Atems B, Jones J (2015) Income inequality and economic growth: A panel VAR approach. Empirical Economics, 48: 1541-1561.

Autor D, Levy F, Murnane R (2003) The skill content of recent technological change: An empirical exploration. Quarterly Journal of Economics, 118: 1279-1333.

Banting K, Myles J (2013) Inequality and the fading of redistributive politics, Vancouver: UBC Press.

Bartik T J (1996) The distributional effects of local labor demand and industrial mix: Estimates using individual panel data. Journal of Urban Economics 40: 150-178.

Bolton K, Breau S (2012) Growing Unequal? Changes in the Distribution of Earnings across Canadian Cities. Urban Studies 49: 1377-1396.

Boschma R (2017) Relatedness as driver of regional diversification: a research agenda. Regional Studies, 51: 351-364.

Boudarbat B, Lemieux T, Riddell C (2006) Recent trends in wage inquality and the wage structure in Canada, in D Green and J Kesselman (Eds.) Dimensions of inequality in Canada. Vancouver, BC: UBC Press, 273-306.

Bourguignon F (2012) La mondialisation de l'inégalité. Seuil, Paris.

Bourne L S (1993) Close Together and Worlds Apart - an Analysis of Changes in the Ecology of Income in Canadian Cities. Urban Studies 30: 1293-1317.

Bradford N (2011) Public policy in Canada: Bringing place in? In Chisholm S (ed) Investing in better places: International perspectives. The Smith Institute, London.

Breau S (2007) Income inequality across Canadian provinces in an era of globalization: explaining recent trends. The Canadian Geographer 51: 72-90. 
Breau S (2015) Rising inequality in Canada: A regional perspective. Applied Geography 61: 5869.

Breau S, Saillant R (2016) Regional income disparities in Canada: exploring the geographical dimensions of an old debate. Regional Studies, Regional Science 3: 464-482.

Breau S, Shin M, Burkhart N (2018) Pulling apart: new perspectives on the spatial dimensions of neighbourhood income disparities in Canadian cities. Journal of Geographical Systems 20: $1-25$

Brynjolfsson E, McAfee A (2014) The second machine age: Work, progress, and prosperity in a time of brilliant technologies, NY: Norton \& Company.

Castells-Quintana D (2018) Beyond Kuznets: Inequality and the size and distribution of cities, Journal of Regional Science 58: 564-580.

Cavanaugh A, Breau S (2018) Locating geographies of inequality: Publication trends across OECD countries. Regional Studies 52: 1225-1236.

Chen W, Myles J, Picot G (2012) Why Have Poorer Neighbourhoods Stagnated Economically while the Richer Have Flourished? Neighbourhood Income Inequality in Canadian Cities. Urban Studies 49: 877-896.

Chokie M, Partridge M D (2008) Low-income dynamics in Canadian communities: A place-based approach. Growth \& Change 39: 313-340.

Coulombe S (1999) Economic growth and provincial disparity: A new view of an old Canadian problem. C.D. Howe Institute, Toronto.

Dahlby B, Ferede E (2013) Income inequality, redistribution and economic growth. University of Calgary's School of Public Policy, SPP Research Papers, Calgary.

Dijkstra L, Poelman H, Rodriguez-Pose A (2019) The geography of EU discontent, Regional Studies. DOI: 10.1080/00343404.2019.1654603

Eichler M (2013) Causal inference with multiple time series: Principles and problems. Philosophical Transactions of the Royal Society A, 371: 20110613.

Elhorst J P (2009) Spatial panel data models. In Fisher M M, Getis A (eds) Handbook of applied spatial analysis Springer, Berlin.

Essletzbichler J, Disslbacher F, Moser M (2018) The victims of neoliberal globalisation and the 
rise of the populist vote: a comparative analysis of three recent electoral decisions. Cambridge Journal of Regions, Economy and Society, 11: 73-94.

Ezcurra R, Rodriguez-Pose A (2013) Does Economic Globalization affect Regional Inequality? A Cross-country Analysis. World Development, 52: 92-103.

Fallah B N, Partridge M D (2007) The elusive inequality-economic growth relationship: are there differences between cities and the countryside? Annals of Regional Science 41: 375-400.

Finnie R (2001) Unequal inequality: the distribution of individuals' earnings by province. Canadian Journal of Regional Science 24: 265-288.

Florida R (2017) The new urban crisis: How our cities are increasing inequality, deepening segregation, and failing the middle class - and what can be done about it. Basic Books.

Forbes K J (2000) A reassessment of the relationship between inequality and growth. American Economic Review 90: 869-887.

Fortin N, Lemieux T (2015) Changes in wage inequality in Canada: An interprovincial perspective. Canadian Journal of Economics 48: 682-713.

Fortin N, Green D A, Lemieux T, Milligan T, Riddell W C (2012) Canadian Inequality: Recent Developments and Policy Options. Canadian Public Policy 38: 121-145.

Frenette M, Green D A, Milligan K (2009) Taxes, Transfers, and Canadian Income Inequality. Canadian Public Policy 35: 389-411.

Granger C, Newbold P (1986) Forecasting economic time series, $2^{\text {nd }}$ edition. San Diego: Academic Press Inc.

Gordon I R (2018) In what sense left behind by globalisation? Looking for a less reductionist geography of the populist surge in Europe. Cambridge Journal of Regions, Economy and Society 11: 95-113.

Graves F, Valpy M (2018) Canada is a tinderbox for populism. The 2019 election could spark it. Macleans.

Graves F, Valpy M (2019) Why Canadians need to wake up about populism. The Star, Wednesday, July $10^{\text {th }}$.

Gray D, Mills J A, Zandvakili S (2004) An analysis of differential provincial income inequality trends in Canada, Research on Economic Inequality 12: 443-461.

Hacker J, Pierson P (2010) Winner-take-all politics: How Washington made the rich richer-and 
turned its back on the middle class, NY: Simon \& Schuster.

Hamilton J (1994) Time series analysis. Princeton: Princeton University Press.

Hulchanski D (2007) The three cities within Toronto: Income polarization among Toronto's neighbourhoods, 1970-2000. Centre for Urban and Community Studies, Research Bulletin No. 41, Toronto.

lammarino S, Rodriguez-Pose A, Storper M (2017) Why regional development matters for Europe's economic future. European Commission WP 07/2017, Luxembourg.

Kemeny T, Rigby D (2012), Trading away what kind of jobs? Globalization, trade and tasks in the US economy. Review of World Economics, 148: 1-16.

Kuznets S (1955) Economic Growth and Income Inequality. American Economic Review, 45: 128.

Lee N (2011) Are innovative regions more unequal? Evidence from Europe. Environment and Planning C 29: 2-23.

Lee N (2016) Growth with inequality? The local consequences of innovation and creativity. In Shearmur R, Carrincazeaux C, Doloreux D. (eds) Handbook on the geographies of innovation, Edward Elgar, Cheltenham.

Lee N, Morris K, Kemeny T (2018) Immobility and the Brexit vote. Cambridge Journal of Regions, Economy and Society 11: 143-163.

Lemieux T, Riddell W C (2016) Who are Canada's top 1 percent? In Green D, Riddell W C, StHilaire F (eds) Income inequality: The Canadian story. Institute for Research on Public Policy, Montreal.

Levernier W, Partridge M D, Rickman D S (1998) Metropolitan-nonmetropolitan distinctions in the determinants of family income inequality. Review of Regional Studies 28: 85-106.

Lobao L, Hooks G, Tickamyer A (2008) Poverty and inequality across space: sociological reflections on the missing-middle subnational scale. Cambridge Journal of Regions, Economy and Society 1: 89-113.

Los B, McCann P, Springford J, Thissen M (2017) The mismatch between local voting and the local economic consequences of Brexit. Regional Studies 51: 786-799.

Lütkepohl, H. (1993) Introduction to multiple time series analysis. Berlin: Springer-Verglag.

MacLachlan I, Sawada R (1997) Measures of income inequality and social polarization in 


\section{Canadian Metropolitan Areas. The Canadian Geographer 41: 377-397.}

MacPhail F (2000) What caused earnings inequality to increase in Canada during the 1980s? Cambridge Journal of Economics 24: 153-175.

McCall L, Percheski C (2010) Income Inequality: New Trends and Research Directions. Annual Review of Sociology, 36: 329-47.

Milanovic B (2016) Global inequality: A new approach for the age of globalization. The Belknap Press of Harvard University Press, Cambridge.

Moretti E (2012) The new geography of jobs. Houghton Mifflin Harcourt, Boston.

Moyser M (2017) Women in Canada: A gender-based statistical report. Statistics Canada, Ottawa.

Murphy B, Veall M (2015) A tale of two cities? The surge of top incomes at the city level in Canada. In Banting K, Chaykowski R, Lehrer S (eds) Thinking outside the box: Innovation in policy ideas. School of Policy Studies, Queen's University, Kingston.

Myles J, Picot G, Pyper W (2000) Neighbourhood inequality in Canadian cities. Statistics Canada, Ottawa.

OECD (1987) Structural adjustment and economic performance. Paris.

OECD (2011) Divided we stand: Why inequality keeps rising. Paris.

OECD (2014a) Focus on top incomes and taxation in OECD countries: Was the crisis a game changer? Paris.

OECD (2014b) Economic Surveys, 2014 - Canada. Paris.

OECD (2018) Divided cities: Understanding intra-urban inequalities. Paris.

Osberg L (2018) The age of increasing inequality - The astonishing rise of Canada's 1\%. James Lorimer \& Company.

Panizza U (2002) Income inequality and economic growth: Evidence from American data, Journal of Economic Growth 7: 25-41.

Partridge M D (1997) Is inequality harmful for growth? Comment, American Economic Review 87: 1019-1032.

Partridge M D (2005) Does income distribution affect US state economic growth? Journal of 
Regional Science 45: 363-394.

Pendakur K, Pendakur R (2011) Aboriginal Income Disparity in Canada. Canadian Public Policy 37: 61-83.

Picot G, Hou F, Coulombe S (2008) Poverty dynamics among recent immigrants to Canada. International Migration Review 42: 393-424.

Piketty, T (2014) Capital in the $21^{\text {st }}$ Century. The Belknap Press of Harvard University.

Polèse M (2017) Why the populist surge has missed Canada. City Journal Autumn: 106-111.

Ray M, Brewis T (1976) The geography of income and its correlates, The Canadian Geographer 20: 41-71.

Rodriguez-Pose A (2018), The revenge of the places that don't matter (and what to do about it). Cambridge Journal of Regions, Economy and Society 11: 189-209.

Rodriguez-Pose A (2012) Trade and Regional Inequality. Economic Geography, 88: 109-136.

Rodriguez-Pose A, Tselios V (2009) Education and Income Inequality in the Regions of the European Union. Journal of Regional Science, 49: 411-437.

Rosen S (1981) The Economics of Superstars. American Economic Review 71: 845-858.

Rupasingha, A., Goetz, S., Freshwater, D (2002) Social and institutional factors as determinants of economic growth: Evidence from the United States counties. Papers in Regional Science. 81: 139-155.

Saillant R (2016) A tale of two countries: How the great demographic imbalance is pulling Canada apart. Nimbus Publishing, Halifax.

Savoie D J (2017) Looking for bootstraps: Economic development in the Maritimes. Nimbus Publishing, Halifax.

Savoie D J (2019) Democracy in Canada - The disintegration of our institutions. McGill-Queen's University Press.

Spicer J S (2018) Electoral Systems, Regional Resentment and the Surprising Success of AngloAmerican Populism. Cambridge Journal of Regions, Economy and Society 11: 115-141.

Storper M (2018) Separate Worlds? Explaining the current wave of regional economic polarization. Journal of Economic Geography 18: 247-270. 
Taylor Z (2018) Ontario's "places that don't matter" send a message. Inroads: The Canadian Journal of Opinion. 44: Winter/Spring.

The Economist (2016) Place-based economic policies as a response to populism. December $1^{\text {st }}$.

Tridico, P (2018) The determinants of income inequality in OECD countries. Cambridge Journal of Economics. 42: 1009-1042.

Veall M R (2010) 2B or Not 2B? What Should Have Happened with the Canadian Long Form Census? What Should Happen Now? Canadian Public Policy 36: 395-399.

Veall M R (2012) Top income shares in Canada: recent trends and policy implications. Canadian Journal of Economics 45: 1247-1272.

Walks R A (2015) Growing divisions: Inequality, neighbourhood poverty and homelessness in the Canadian city. In Filion P, Moos M, Vinodrai T, Walker R (eds) Canadian Cities in Transition: Perspectives for an Urban Age, Oxford University Press, Toronto.

Williamson J (1965) Regional Inequality and the Process of National-Development - a Description of the Patterns. Economic Development and Cultural Change, 13: 1-84. 
Figure 1. Changes in inequality across OECD countries, early-1990s to late-2000s

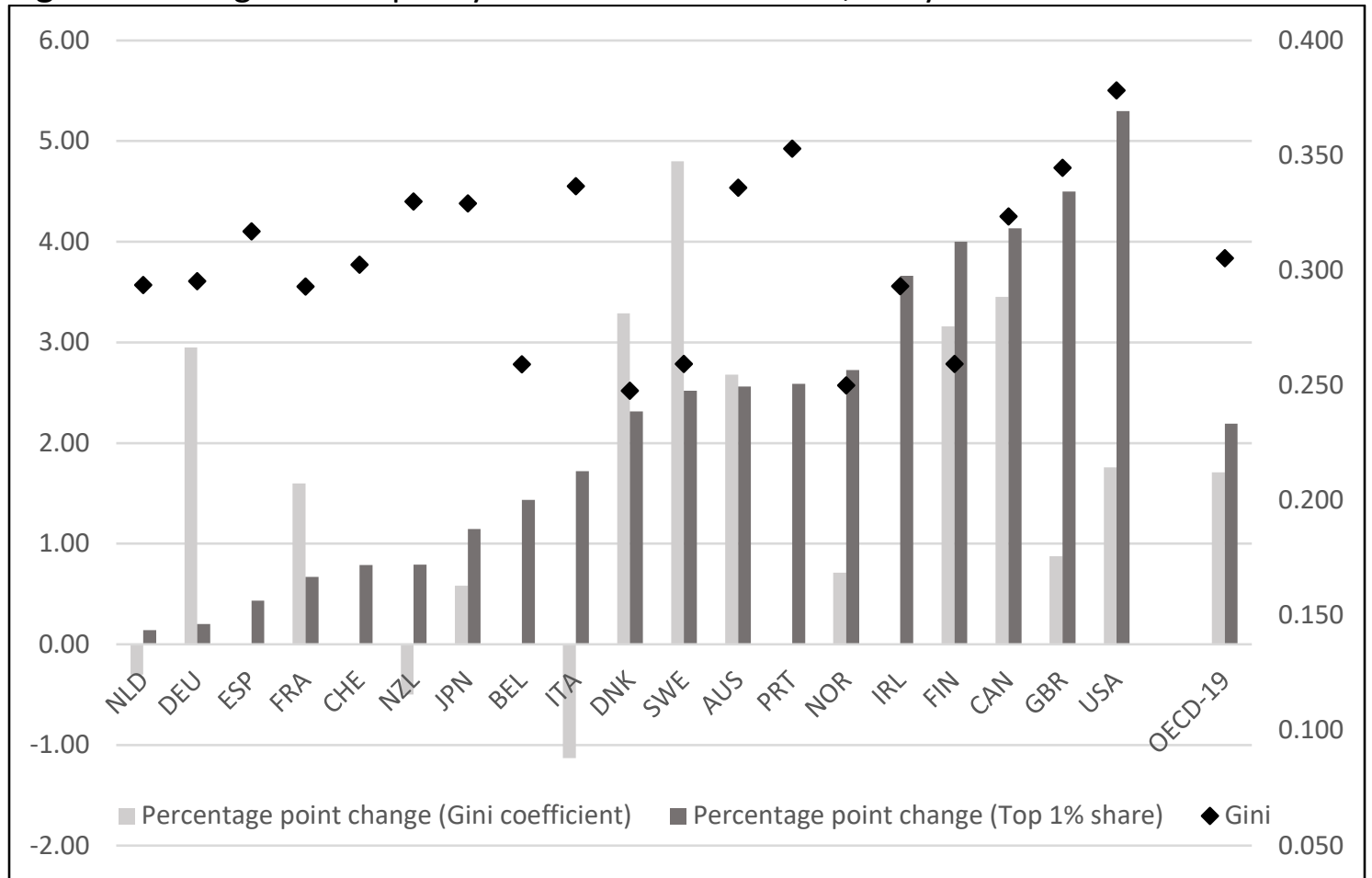

Source: OECD (2011). Gini coefficients are based on disposable household income figures.

Figure 2. Causes and consequences of regional income inequality

\begin{tabular}{|c|c|c|}
\hline \multicolumn{2}{|c|}{ Causes } & Consequences \\
\hline Global/macro forces & \multirow{4}{*}{$\begin{array}{l}\text { Local forces } \\
\text { Labour market \& economic } \\
\text { conditions } \\
\text { - Economic development } \\
\text { - Unemployment rate } \\
\text { - Part-time/self-employed } \\
\text { - Industrial composition }\end{array}$} & Local outcomes \\
\hline Technological change & & Political instability \\
\hline International trade & & Economic growth \\
\hline Outsourcing & & Social effects \\
\hline Political institutions & Socio-demographic factors & $\begin{array}{l}\text { - Social mobility } \\
\text { - Educational performance }\end{array}$ \\
\hline \multirow{4}{*}{ Taxes and transfers } & $\begin{array}{l}\text { - Female participation rate } \\
\text { - Visible minorities }\end{array}$ & Health outromes \\
\hline & - Age composition & : Mortality \\
\hline & Local institutional factors & - Morbidity \\
\hline & $\begin{array}{l}\text { - Minimum wages } \\
\text { : Unionization rates } \\
\text { - Provincial transfers }\end{array}$ & \\
\hline
\end{tabular}


Figure 3: Regional Gini coefficients, by province (2011)

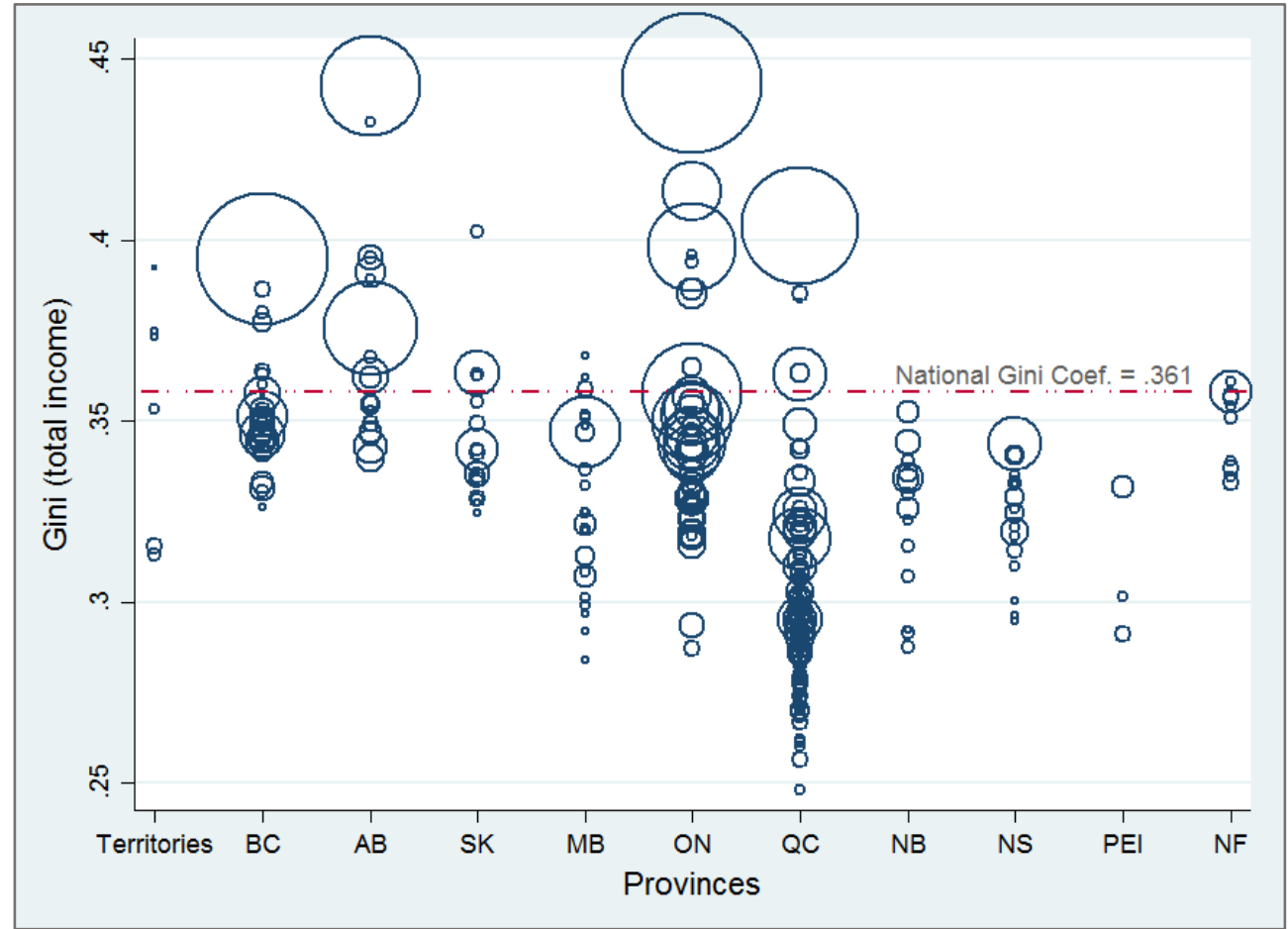

Figure 4: Gini coefficients, 1981 to 2011

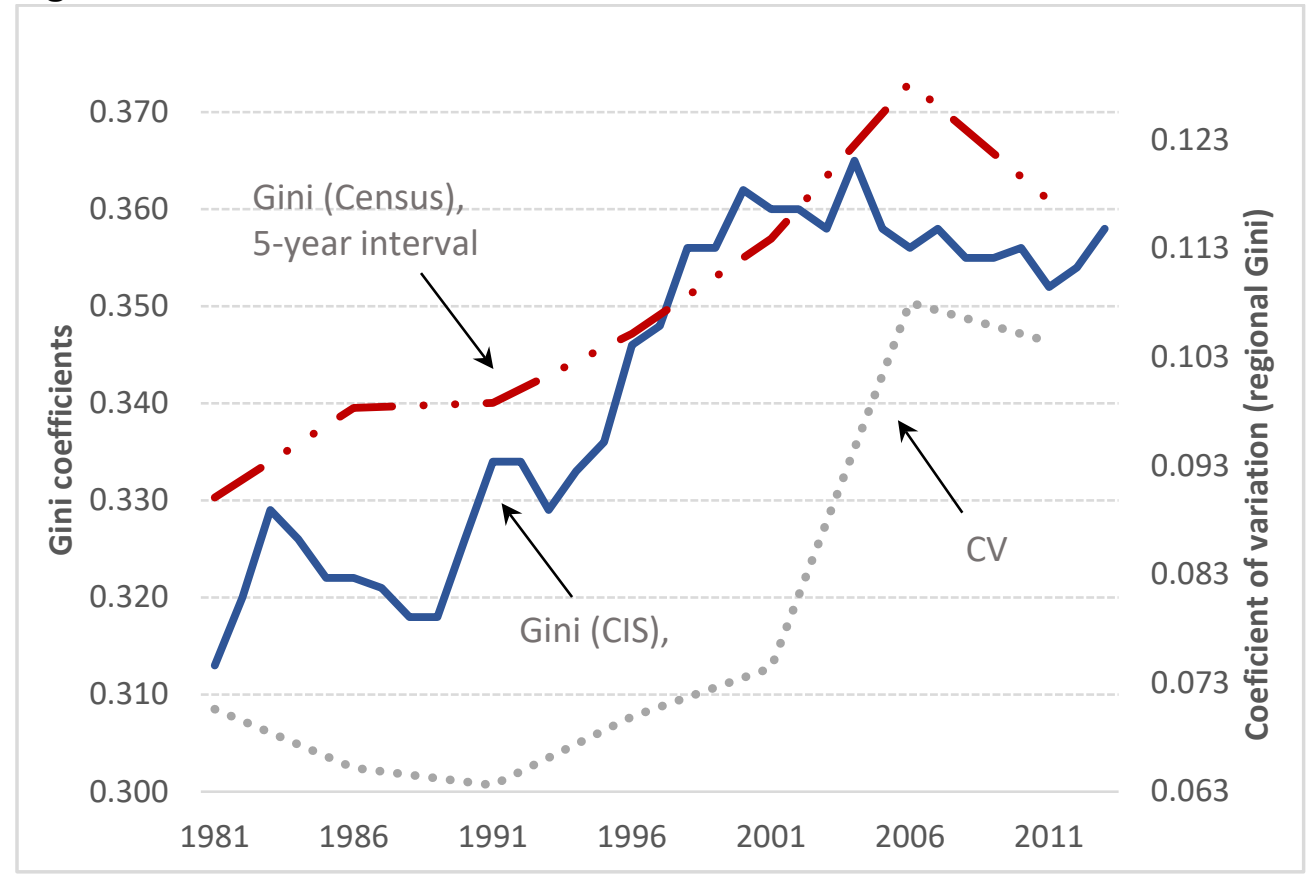


Figure 5: Percentage change in regional Gini coefficients, 1981 to 2011

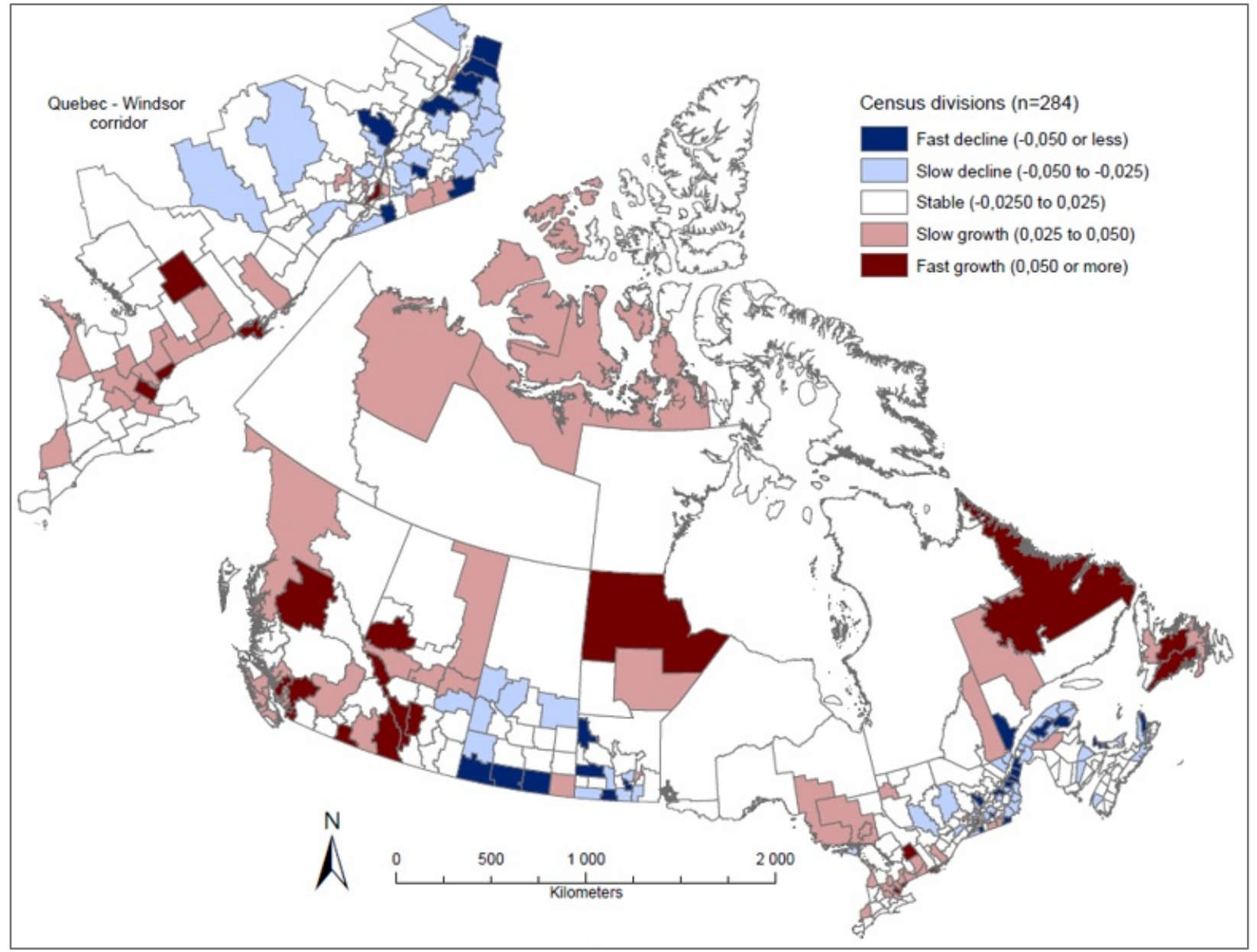


Table 1: Variables and basic descriptive statistics, 2011

\begin{tabular}{|c|c|c|c|c|}
\hline \multicolumn{2}{|c|}{ Variable } & Description and unit & Mean & Std. Dev. \\
\hline \multicolumn{5}{|c|}{ Dependent variables } \\
\hline \multicolumn{2}{|c|}{ Gini coefficient (Eq. 1) } & Using total income, individuals aged 15-64 & 36.1 & 4.4 \\
\hline \multirow{2}{*}{\multicolumn{2}{|c|}{ Average annual growth (Eq. 2) }} & $\%$ calculated on 5 - and 10 -year growth cycles & $4.2 /$ & $1.1 /$ \\
\hline & & of regional median total income & 3.3 & 0.8 \\
\hline \multicolumn{5}{|c|}{ Independent variables } \\
\hline \multicolumn{5}{|c|}{ Labour market and economic variables } \\
\hline \multicolumn{2}{|c|}{ Median wages } & Median wages in $\$ 2002 \$$ & 39418 & 7546 \\
\hline \multicolumn{2}{|c|}{ Unemployment rate } & $\%$ of the labour force unemployed & 6.5 & 4.2 \\
\hline \multicolumn{2}{|c|}{ Part-time workers (\%) } & $\%$ of part-time workers & 12.6 & 2.4 \\
\hline \multicolumn{5}{|c|}{ Socio-demographic variables } \\
\hline \multicolumn{2}{|c|}{ Female participation rate } & $\%$ of female workers in the labour force & 48.3 & 1.6 \\
\hline \multicolumn{2}{|c|}{ Visible minorities (\%) } & $\%$ of visible minorities in the labour force & 17.6 & 16.8 \\
\hline \multicolumn{2}{|c|}{ Education ratio } & $\%$ of $<$ high school $+\%$ of $\geq$ university degree & 37.6 & 8.1 \\
\hline \multicolumn{2}{|c|}{ Young (\%) } & $\%$ of population age $<15$ & 17.0 & 2.4 \\
\hline \multicolumn{2}{|c|}{ Senior (\%) } & $\%$ of population age $>65$ & 13.9 & 3.2 \\
\hline \multicolumn{5}{|c|}{ Industrial variables } \\
\hline \multicolumn{2}{|c|}{ Primary sector (\%) } & $\%$ of workers in primary ind. (raw materials) & 3.4 & 4.6 \\
\hline \multicolumn{2}{|c|}{ Secondary sector (\%) } & $\%$ of workers in mainly manuf. activities & 17.1 & 5.4 \\
\hline & Resource-intensive ind. (\%)* & $\%$ ind. highly dependent on natural resources & 3.1 & 2.3 \\
\hline & Labour-intensive ind. (\%)* & $\%$ ind. with high proportion of labour costs & 1.7 & 1.1 \\
\hline & Scale-intensive ind. (\%)* & $\%$ ind. with long production runs & 2.9 & 2.5 \\
\hline & Differentiated goods (\%)* & $\%$ ind. tailoring to varied demand characs. & 1.5 & 1.1 \\
\hline & Science-based ind. (\%)* & $\%$ ind. with rapid app. of scientific advance & 1.3 & 1.0 \\
\hline \multicolumn{2}{|c|}{ Construction (\%) } & $\%$ of workers employed in construction ind. & 6.4 & 2.0 \\
\hline \multicolumn{2}{|c|}{ Tertiary sector (\%) } & $\%$ of workers employed in basic services & 22.9 & 3.2 \\
\hline \multicolumn{2}{|c|}{ Transportation (\%) } & $\%$ of workers in transportation services & 4.2 & 1.3 \\
\hline \multicolumn{2}{|c|}{ Communications (\%) } & $\%$ of workers in communications services & 3.4 & 1.4 \\
\hline \multicolumn{2}{|c|}{ Utilities (\%) } & $\%$ of workers in utilities & 1.0 & 1.1 \\
\hline \multicolumn{2}{|c|}{ Retail (\%) } & $\%$ of workers in retail trade & 9.6 & 1.4 \\
\hline \multicolumn{2}{|c|}{ Wholesale (\%) } & $\%$ of workers in wholesale trade & 4.6 & 1.6 \\
\hline Qua & ternary services (\%) & $\%$ of workers in information based services & 56.4 & 7.3 \\
\hline FIR & $R E(\%)$ & $\%$ of workers in finance, ins. and real estate & 6.1 & 2.6 \\
\hline $\mathrm{Pu}$ & blic administration (\%) & $\%$ of workers in public administration & 8.3 & 5.6 \\
\hline $\mathrm{Ed}$ & ucation and health (\%) & $\%$ of workers in education and health & 20.6 & 3.4 \\
\hline & ts, entertainment and rec. (\%) & $\begin{array}{l}\% \text { of workers in arts, entertainment, } \\
\text { recreation and accommodation services }\end{array}$ & 6.1 & 1.8 \\
\hline & $3 \mathrm{~S}(\%)$ & $\begin{array}{l}\% \text { of workers in knowledge intensive } \\
\text { business services }\end{array}$ & 6.9 & 2.9 \\
\hline Insti & itutional variables & & & \\
\hline Mini & imum wages & $\$ 2002$, provincial-level variable ${ }^{a}$ & 11.7 & 0.69 \\
\hline Tran & sfers to persons (per capita) & $\$ 2002$, provincial-level variable ${ }^{b}$ & 6163.5 & 570.4 \\
\hline Unic & onization rate (\%) & $\%$ of workers unionized, provincial-level var. ${ }^{c}$ & 31.1 & 5.4 \\
\hline
\end{tabular}

Notes: The census long-form dataset is the primary source of information for all variables with the exception of institutional variables. * Refers to the percentage of workers in industries; ${ }^{a}$ Human Resources and Skills

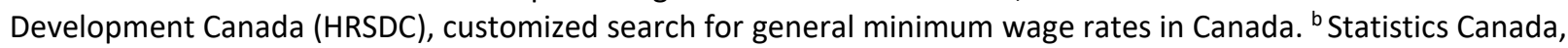
Table 384-0004. ${ }^{c}<$ odesi> [On-line] database created by the Ontario Council of University Libraries. $\S$ All real (\$2002) dollar values deflated using the provincial CPI. 
Table 2: Fixed effects spatial error model results (causes)

\begin{tabular}{|c|c|c|c|}
\hline \multirow[b]{2}{*}{ Independent variables } & \multicolumn{3}{|c|}{ Dependent variable $=$ Gini coefficient } \\
\hline & $\begin{array}{c}\text { (1) } \\
\text { Parsimonious } \\
\text { model }\end{array}$ & $\begin{array}{c}\text { (2) } \\
\text { Aggregate } \\
\text { industries }\end{array}$ & $\begin{array}{c}\text { (3) } \\
\text { Full industria } \\
\text { specification }\end{array}$ \\
\hline \multicolumn{4}{|l|}{ Labour market and economic variables } \\
\hline Median wages & $.001 * * *$ & $.001 * * *$ & $.001 *$ \\
\hline (Median wages) $^{2}$ & .001 & .001 & $.001 * *$ \\
\hline Unemployment rate & $.084 * * *$ & $.076 * * *$ & $.071 * * *$ \\
\hline Part-time workers (\%) & $.219 * * *$ & $.191 * * *$ & $.213 * * *$ \\
\hline \multicolumn{4}{|l|}{ Socio-demographic variables } \\
\hline Female participation rate & $.117 * * *$ & $.045 * * *$ & $.020 * * *$ \\
\hline Visible minorities (\%) & $.101 * * *$ & $.090 * * *$ & $.068 * * *$ \\
\hline Education ratio & $.085 * * *$ & $.097 * * *$ & $.082 * * *$ \\
\hline Young (\%) & $.084 * * *$ & $.051 * * *$ & $.135 * * *$ \\
\hline Senior (\%) & $.100 * * *$ & $.104 * * *$ & $.097 * * *$ \\
\hline \multicolumn{4}{|l|}{ Industrial sector variables } \\
\hline Secondary sector (\%) & & $-.063 * * *$ & \\
\hline Resource-intensive industries (\%) & & & $-.087 * * *$ \\
\hline Labour-intensive industries (\%) & & & $-.047 * * *$ \\
\hline Scale-intensive industries (\%) & & & $-.102 * * *$ \\
\hline Differentiated goods (\%) & & & -.048 \\
\hline Science-based industries (\%) & & & -.073 \\
\hline Tertiary sector (\%) & & $.039 * * *$ & \\
\hline Transportation (\%) & & & $-.085 * * *$ \\
\hline Communications (\%) & & & -.031 \\
\hline Utilities (\%) & & & $.134 * * *$ \\
\hline Retail trade (\%) & & & -.013 \\
\hline Wholesale trade (\%) & & & -.010 \\
\hline Quaternary sector (\%) & & -.003 & \\
\hline FIRE (\%) & & & $.075 * *$ \\
\hline Public administration (\%) & & & $-.087 * * *$ \\
\hline Education and health (\%) & & & -.013 \\
\hline Arts, entertainment and rec. (\%) & & & $.115 * * *$ \\
\hline KIBS (\%) & & & $.241 * * *$ \\
\hline \multicolumn{4}{|l|}{ Institutional variables } \\
\hline Minimum wages & $-.004 * * *$ & -.001 & $-.003 * * *$ \\
\hline Transfers to persons (per capita) & -.001 & $-.001 *$ & $.001 * *$ \\
\hline Unionization rate (\%) & $-.001 * * *$ & $-.001 * * *$ & $-.001 * * *$ \\
\hline Decade dummies & $Y$ & Y & $Y$ \\
\hline Intercept & $.211 * * *$ & $.251 * * *$ & $.263 * * *$ \\
\hline Lambda & $.349 * * *$ & $.354 * * *$ & $.328 * * *$ \\
\hline Sigma & $.018 * * *$ & $.018 * * *$ & $.017^{* * *}$ \\
\hline$R^{2}$ & .494 & .523 & .586 \\
\hline Log likelihood function & 5082.6 & 5142.1 & 5270.5 \\
\hline$N$ (cross section number) & $1988(284)$ & $1988(284)$ & $1988(284)$ \\
\hline
\end{tabular}

Notes: ${ }^{*}, * *$ and ${ }^{* * *}$ denote statistical significance at the $.10, .05$ and .01 levels, respectively. 
Table 3: Fixed effects spatial lag model results (consequences)

\begin{tabular}{|c|c|c|c|c|}
\hline \multirow[b]{3}{*}{ Independent variables } & \multicolumn{4}{|c|}{ Dependent variable = Average annual growth } \\
\hline & \multicolumn{2}{|c|}{$\begin{array}{c}\text { Short-term (i.e., 5-year) } \\
\text { effects }\end{array}$} & \multicolumn{2}{|c|}{$\begin{array}{c}\text { Medium-term (i.e., 10-year) } \\
\text { effects }\end{array}$} \\
\hline & $\begin{array}{c}(1) \\
\text { Parsimonious } \\
\text { model }\end{array}$ & $\begin{array}{c}\text { (2) } \\
\text { Full } \\
\text { specification }\end{array}$ & $\begin{array}{c}(3) \\
\text { Parsimonious } \\
\text { model }\end{array}$ & $\begin{array}{c}\text { (4) } \\
\text { Full } \\
\text { specification }\end{array}$ \\
\hline Inequality (Gini coefficient) & $.083^{* * *}$ & $.074 * * *$ & $-.042 * * *$ & $-.041 * *$ \\
\hline Ln(Median income) & $-.008 * * *$ & $-.080 * * *$ & $-.069 * * *$ & $-.093 * * *$ \\
\hline \multicolumn{5}{|c|}{ Labour market and economic variables } \\
\hline Unemployment rate & & $.065 * * *$ & & -.003 \\
\hline Part-time workers (\%) & & -.025 & & $-.035 * *$ \\
\hline \multicolumn{5}{|l|}{ Socio-demographic variables } \\
\hline Female participation rate & & $.106 * * *$ & & .001 \\
\hline Visible minorities (\%) & & -.001 & & .002 \\
\hline Education ratio & & $-.040 * * *$ & & $-.024 * * *$ \\
\hline Young (\%) & & $.056 * *$ & & $.035 *$ \\
\hline Senior (\%) & & -.044 & & $-.045 *$ \\
\hline \multicolumn{5}{|l|}{ Institutional variables } \\
\hline Minimum wages & & $.003 * * *$ & & $-.002 * * *$ \\
\hline Transfers to persons (per capita) & & $.001 * * *$ & & .001 \\
\hline Unionization rate $(\%)$ & & $-.001 * * *$ & & $.001 * * *$ \\
\hline Industrial share variables & $\mathrm{N}$ & $\mathrm{Y}$ & $\mathrm{N}$ & Y \\
\hline Decade dummies & $\mathrm{Y}$ & $\mathrm{Y}$ & Y & Y \\
\hline Intercept & $.057 * * *$ & $.785 * * *$ & $.705 * * *$ & $.942 * * *$ \\
\hline Rho & $.875 * * *$ & $.751 * * *$ & $.677^{* * *}$ & $.507 * * *$ \\
\hline$R^{2}$ & .728 & .434 & .564 & .338 \\
\hline Log likelihood function & 5391.3 & 5556.9 & 3460.4 & 3549.7 \\
\hline$N$ (cross section number) & 1704 (284) & $1704(284)$ & $852(284)$ & 852 (204) \\
\hline
\end{tabular}

Notes: ${ }^{*}, * *$ and ${ }^{* * *}$ denote statistical significance at the $.10, .05$ and .01 levels, respectively. 
Table 4: Sensitivity analysis of the equity/growth trade-off

\begin{tabular}{|c|c|c|c|c|}
\hline \multirow[b]{2}{*}{ Variable/model specification } & \multicolumn{2}{|c|}{$\begin{array}{c}\text { Short-term (i.e., 5-year) } \\
\text { effects }\end{array}$} & \multicolumn{2}{|c|}{$\begin{array}{c}\text { Medium-term } \\
\text { (i.e., 10-year) effects }\end{array}$} \\
\hline & $\begin{array}{c}\text { Coef. on } \\
\text { inequality }\end{array}$ & $\begin{array}{c}\text { Standard } \\
\text { error }\end{array}$ & $\begin{array}{c}\text { Coef. on } \\
\text { inequality }\end{array}$ & $\begin{array}{c}\text { Standard } \\
\text { error }\end{array}$ \\
\hline \multicolumn{5}{|l|}{ Different spatial weights matrices } \\
\hline Gini with rook (benchmark) & $.083 * * *$ & (.019) & $-.042 * * *$ & $(.016)$ \\
\hline Gini with $K 3$-nearest neighbour & $.062 * * *$ & $(.020)$ & $-.049 * * *$ & $(.017)$ \\
\hline Gini with distance based matrix & $.065^{* * *}$ & $(.021)$ & $-.059 * * *$ & $(.018)$ \\
\hline \multicolumn{5}{|l|}{ Inequality indicators } \\
\hline Gini coefficient (benchmark) & $.083 * * *$ & (.019) & $-.042 * * *$ & $(.016)$ \\
\hline Theil index & $.025 * * *$ & $(.008)$ & $-.014 *$ & $(.008)$ \\
\hline Half squared CV (GE2) & $.001 *$ & $(.001)$ & -.002 & $(.001)$ \\
\hline \multicolumn{5}{|l|}{ Income concept for growth variable } \\
\hline Median total income (benchmark) & $.083 * * *$ & (.019) & $-.042 * * *$ & $(.016)$ \\
\hline Median wages & $.074 * * *$ & $(.027)$ & $-.056 * *$ & $(.023)$ \\
\hline Gini coefficient (wages) & $.151 * * *$ & $(.018)$ & $-.029 *$ & $(.016)$ \\
\hline
\end{tabular}

Table 5: Structural PVAR analysis of inequality-growth Granger causality

\begin{tabular}{|c|c|c|c|c|}
\hline & \multicolumn{4}{|c|}{ (A) Short-term (i.e., 5-year) lags } \\
\hline & \multicolumn{2}{|c|}{ (1) Parsimonious } & \multicolumn{2}{|c|}{ (2) Augmented } \\
\hline & Gini & Growth (5y) & Gini & Growth (5y) \\
\hline Ginit-1 & -9.52 & 10.92 & $-.963^{*}$ & $2.093 * * *$ \\
\hline Growth (5y) t-1 & -.248 & .445 & -0.070 & $.261 * * *$ \\
\hline Median income $\mathrm{t}-1$ & & & $-.010 * * *$ & $.011 * * *$ \\
\hline \multirow[t]{4}{*}{$N$ (cross section number) } & $1136(284)$ & $1136(284)$ & $1136(284)$ & $1136(284)$ \\
\hline & \multicolumn{4}{|c|}{ (B) Medium-term (i.e., 10-year) lags } \\
\hline & \multicolumn{2}{|c|}{ (1) Parsimonious } & \multicolumn{2}{|c|}{ (2) Augmented } \\
\hline & Gini & Growth (10y) & Gini & Growth (10y) \\
\hline Gini $t-1$ & $-.517 *$ & $-1.32 * * *$ & .039 & $-.545 * * *$ \\
\hline Growth $(10 y) t-1$ & $.274 * * *$ & $-.452 * * *$ & $.462 * * *$ & $-.188^{*}$ \\
\hline Median income $t_{-1}$ & & & $.020^{*}$ & $.028 * * *$ \\
\hline$N$ (cross section number) & $284(284)$ & $284(284)$ & $284(284)$ & $284(284)$ \\
\hline
\end{tabular}

